\title{
Role of Computed Tomographic Scanning in Pediatric Head Injury: An Observational Cohort of Data of 60 Patients
}

\author{
Pankaj Sharma1,2 \\ ${ }^{1}$ Luanda Medical Center, Luanda, Angola \\ ${ }^{2}$ Goa Medical College, Goa, India \\ Email:sharmapankaj29@gmail.com
}

Received 30 October 2015; accepted 26 December 2015; published 29 December 2015

Copyright (c) 2015 by author and Scientific Research Publishing Inc.

This work is licensed under the Creative Commons Attribution International License (CC BY). http://creativecommons.org/licenses/by/4.0/

(c) (i) Open Access

\begin{abstract}
Pediatric head injury is one of the major health problems. That can be easily evaluated by computed tomographic scanning. This study describes the various findings of pediatric head trauma seen on CT scan, the timely diagnosis of which plays a vital role in prognosis, especially in semiurban and remote location where the decision for tertiary referral is important. Timely intervention in traumatic brain injury cases reduces morbidity and mortality. Cerebral edema, which is the most common intracranial lesion, can be promptly managed by medicosurgical support with ICP monitoring, thereby improving the overall prognosis. Other lesions commonly seen are subdural hematomas and skull fractures. Limitations of radiographs, ultrasound and MRI in these acute cases, highlight the benefit of CT scans.
\end{abstract}

\section{Keywords}

Computed Tomographic Scanning, Traumatic Brain, Injury, Subdural Hematoma

\section{Introduction}

Traumatic brain injury is a major health problem. The head injury is the most common cause of death between 1 and 15 years ( $15 \%$ of all deaths). In the age group of 5 - 15 years, TBI accounts for $25 \%$ of deaths [1]. The role of a radiologist in evaluating an acutely injured child has been an ever-increasing one, particularly since the advent of CT in 1972 [2]. CT scan is very accurate in diagnosing hyperdense hematomas, contusions, skull fractures etc, and its role is poor in assessing diffuse axonal injury (DAI) which affects minority of children. CT scan findings like "slit like" lateral ventricles, compression of the 3rd ventricle and basal cisterns can indicate 
abnormal ICP. CT scan variables are independent prognostic variable, apart from age, GCS and papillary reaction [3]. This case series addresses the role of CT scan in diagnosing various lesions in children presenting with head injury, which in addition to clinical information will be helpful in initiating optimal management.

\section{Patients \& Methods}

This study was done prospectively in 60 children consecutively presenting with head injury in the department of radiology of Goa medical college and hospital in a span of three years (1995-1998). This study was approved by ethical committee of Goa University, under the postgraduate curriculum of medicine. Out of 60 children with head injury in age-group 0 - 12 years, three children were birth related injury where as the rest were related to motor vehicle accidents, fall from height and other mechanisms. These children were referred to the radiology department. A non-contrast computed tomographic scanning of the head was done on Somatom SR scanner by taking axial scans of $5 \mathrm{~mm} / 10 \mathrm{~mm}$ slice thickness, in the majority of children within $0-12$ hours. None these cases required contrast study, after evaluation of plain study. Sedation was done as and when required in case to case basis after obtaining informed consent.

\section{Results}

The age distribution of 60 children presenting with head injury was as follows: 11 were between 0 - 1 year (18\%), 16 were between 1 - 5 years (26\%), 24 were between 5 - 10 years (40\%) and 9 were between 10 - 12 years $(15 \%)$.

There were 31 children with skull fractures, 24 had linear type (77\%), 6 had depressed type (19\%), and 1 had the diastasis of suture line (3\%). The location of fractures was in frontal bone (10 cases-32\%), skull base region (1 case-3\%), temporal bone ( 7 cases-22\%), parietal bone (11 cases-35\%), occipital bone (2 cases-6\%).

In this study, 11 cases had intra-axial contusions, 12 cases had extra-axial hematomas and four cases had scalp hematomas. Out of the 12 extra-axial hematomas cases, 6 (50\%) had a subdural hematoma, 3 (25\%) had extradural hematoma and 3 (25\%) had subarachnoid hemorrhage. The distribution of scalp hematomas were, 1 patient had a subgaleal hematoma due to non-birth related injury and 3 patients had cephalhematoma due to birth injury. Computed tomographic scanning study revealed normal findings in 11cases, diffuse cerebral edema in 14 cases, intra-axial lesion (contusions) in 11 cases, extra-axial lesion in 12 cases, skull fractures in 31 cases and scalp hematoma in 4 cases.

\section{Discussion}

$\mathrm{HI}$ has a high emotional, psychosocial and economic impact because these cases often have comparatively longer hospital stays, and 5\% - 10\% of them require long term care after discharge [4]. Head Injury in infancy and childhood has been documented as the single most common cause of death [5]. Head injury is more common in children older than five years in this study (Chart 1) as compared to study by Bhargava et al., where it was found to be more common in 1 - 5 years of age-group [6].

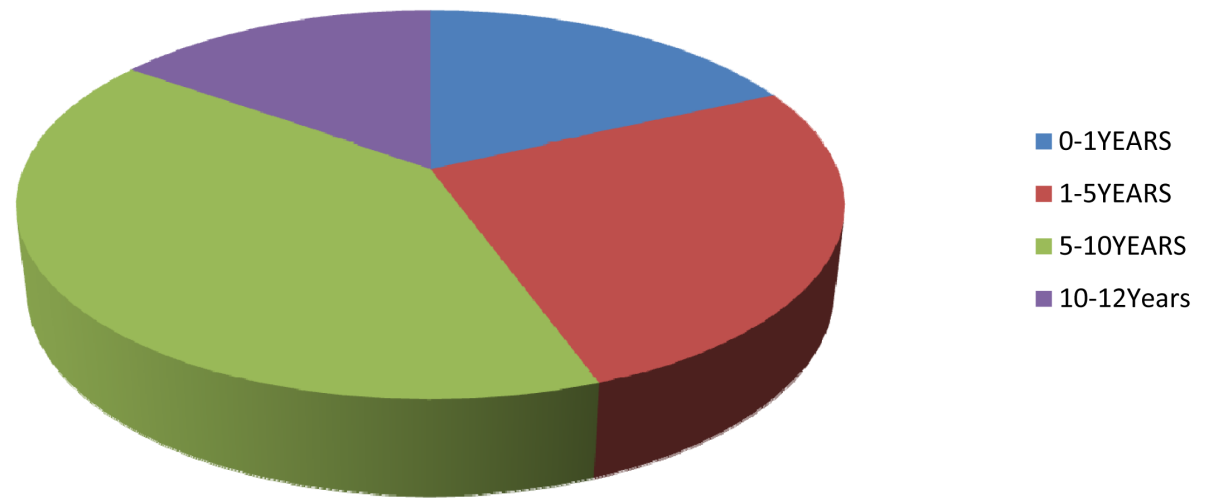


In a study by tomberg et al. 1996, in pediatric head injury, the most frequent finding was diffuse brain swelling with CT evidence of ventricular and cisternal compression or obliteration [7] [8], as is noted in this case series. Third ventricular compression is a more sensitive CT index of increased ICP, a finding with cisternal obliteration indicates a worse prognosis [9]. The CT appearance of diffuse swelling may develop more readily in children because of the less amount of cerebro-spinal fluid available for displacement, however diffuse swelling may have a relatively benign course, unless there is a severe primary injury or a secondary hypotensive insult [10].

Subdural hematoma is a more common extra-axial collection in pediatric head trauma as noted in this study, more commonly seen in non-accidental trauma in children [11]. EDH is extremely uncommon in infants [12] and relatively uncommon in older children. EDH was found in less than $1 \%$ of all children with craniocerebral trauma. Similar findings were noted in this case series. Epidural hematoma may occur after relatively minor head trauma and in alert children with non-focal neurologic examinations, a finding which can be accurately evaluated by CT scan [11].

Skull fractures result from direct impact to the calvarium and are important because of their association with intracranial injury, the leading cause of traumatic death in childhood [13] [14]. Fractures of the skull, present in $23 \%$ of cases, seemed to be associated with high mortality even after type of lesion is considered [15]. The incidence of skull fractures ranged from 2 - 20 percent in a study by Schutzmansa et al. [16], as compared to our study showing the incidence of 50 percent (Chart 2). Of all types of pediatric skull fractures, linear fracture is by far most common (>80\%) and usually involve the parietal bone, as is seen in this case series [17].

There were 37 children with significant lesions and 6 children with depressed fracture, representing more than 50 percent cases that would require immediate medicosurgical ICU care for positive outcomes. Prognostically, the most unfavorable findings were shearing injury, intracerebral and subdural hematomas combined with brain swelling and parenchymal damage [7]. Therefore an urgent CT scan in pediatric head injury would significantly alter the management and eventual outcome in pediatric cases [18].

Cephalhematoma is a subperiosteal hemorrhage related to birth trauma or intrumentation during delivery and usually located in the parietal or occipital bone [19] as is seen in this case series.

SDH occurs in the asymptomatic neonate after delivery [20] whereas diffuse cerebral swelling is the most common lesion in non-birth related injuries in TBI.

Ct scan plays a vital role in diagnosis of almost all pathological lesions of pediatric head injuries except in DAI and microbleeds. In head injury, where scanning time has to be minimal, role of CT scan is superior to MRI.

Limitations of this study are: 1 ) the lack of accurate follow-up of individual cases (due to non-availibility of PACS in this institution during this period); 2) treatment outcome during the study period cannot be compared the present scenario, due to advancement in treatment protocol; 3) DAI could not be accurately differentiated from diffuse cerebral edema (where MRI plays a superior role); 4) lethal cancer risk could not be assessed as it required longterm follow-up.

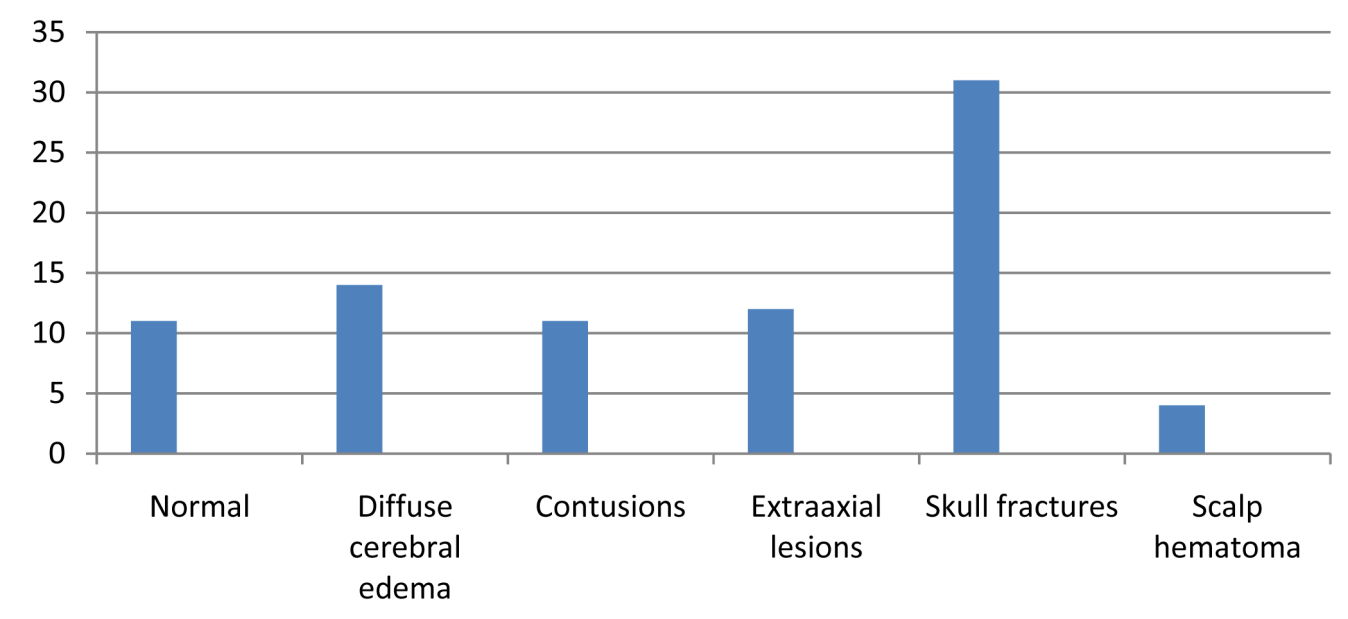




\section{Conclusions}

The study correlates well with current TBI scenario.

The advantages of CT scan are: 1) It plays a vital role in initial and follow-up studies of TBI in rural and suburban regions, where MRI is not readily available. 2) CT scan is a very good screening tool in minor head injury.

The disadvantages are: 1) There may be as high as 1 case of lethal cancer for every 1000 CT scans performed in a young child [21]. Due to risk of ionizing radiation, CT scan should be limited to acutely trauma cases with significant neurologic impairment. Follow-up can be advised using MRI [2] and ultrasound, especially in tertiary centres. 2) Also DAI is poorly evaluated by CT scan. MRI is a valuable adjunct to CT in the follow-up cases, especially in tertiary centres. Radiographs have a highly limited role in assessing intracranial lesions in TBI. CT scans can be classified according to the simple seven point grading [3].

\section{Acknowledgements}

The author would like to thank his radiology guide, Dr Jeevan Vernekar, Goa Medical College. Also grateful to Dr. Swati Sharma, for her suggestions in writing this manuscript.

\section{References}

[1] Yager, J.V., Johnston, B. and Seishia, S.S. (1990) Coma Scales in Pediatric Practice. American Journal of Diseases of Children, 144, 1088-1091.

[2] Kelly, A.B., Zimmerman, R.D., Snow, R.B., Gandy, S.E., Heier, L.A. and Deck, M.D. (1988) Head Trauma: Comparison of MR and CT-Experience in 100 Patients. American Journal of Neuroradiology, 9, 699-708.

[3] Wardlaw, J.M., Easton, V.J., Statham, P. and Which, C.T. (2002) Features Help Predict Outcome after Head Injury? Journal of Neurology, Neurosurgery, and Psychiatry, 72, 188-192.

[4] Cakmakci, H. (2009) Essentials of Trauma: Head and Spine. Pediatric Radiology, 39, 391-405.

[5] Luerssen, T.G., Klauber, M.R. and Marshall, L.F. (1988) Outcome from Head Injury Related to Patient’s Age: A Longitudinal Prospective Study of Adult and Pediatric Head Injury. Journal of Neurosurgery, 68, 409-416.

[6] Bhargava, P., Singh, R., Prakash, B. and Sinha, R. (2011) Pediatric Head Injury: An Epidemiological Study. Journal of Pediatric Neurosciences, 6, 97-98.

[7] Tomberg, T., Rink, U., Pikkoja, E. and Tikk, A. (1996) Computerized Tomography and Prognosis in Paediatric Head Injury. Acta Neurochirurgica, 138, 543-548.

[8] Bruce, D.A., Alavi, A., Bilaniuk, L., Dolinskas, C., Obrist, W. and Uzzell, B. (1981) Diffuse Cerebral Swelling Following Head Injuries in Children: The Syndrome of "Malignant Brain Edema”, Journal of Neurosurgery, 54, 170-178.

[9] Teasdale, E., Cardoso, E., Galbraith, S. and Teasdale, G. (1984) CT Scan in Severe Diffuse Head Injury: Physiological and Clinical Correlations. Journal of Neurology, Neurosurgery, \& Psychiatry, 47, 600-603.

[10] Lang, D.A., Teasdale, G.M., Macpherson, P. and Lawrence, A. (1994) Diffuse Brain Swelling after Head Injury: More Often Malignant in Adults than Children? Journal of Neurosurgery, 80, 675-680.

[11] Schutzman, S.A., Barnes, P.D., Mantello, M. and Scott, R.M. (1993) Epidural Hematomas in Children. Annals of Emergency Medicine, 22, 535-541.

[12] Leggate, J.R., Lopez-Ramos, N., Genitori, L., Lena, G. and Choux, M. (1989) Extradural Hematoma in Infants. British Journal of Neurosurgery, 3, 533-539.

[13] Quayle, K.S., Jaffe, D.M., Kuppermann, N., Kaufman, B.A., Lee, B.C., Park, T.S. and McAlister, W.H. (1997) Diagnostic Testing for Acute Head Injury in Children: When Are Head Computed Tomography and Skull Radiographs Indicated? Pediatrics, 99, E11.

[14] Shane, S.A. and Fuchs, S.M. (1997) Skull Fractures in Infants and Predictors of Associated Intracranial Injury. Pediatric Emergency Care, 13, 198-203.

[15] Kraus, J.F., Fife, D. and Conroy, C. (1987) Pediatric Brain Injuries: The Nature, Clinical Course, and Early Outcomes in a Defined United States’ Population. Pediatrics, 79, 501-507.

[16] Schutzman, S.A. and Greenes, D.S. (2001) Pediatric Minor Head Trauma. Annals of Emergency Medicine, 37, 65-74.

[17] Caviness, A.C. (2015) Skull Fractures in Children. http://www.uptodate.com/contents/skull-fractures-in-children

[18] Wardlaw, J.M., Easton, V.J. and Statham, P. (2002) Which CT Features Help Predict Outcome after Head Injury? 
Journal of Neurology, Neurosurgery \& Psychiatry, 72, 188-192.

[19] Ketonen, L.M., Hiwatashi, A., Sidhu, R. and Westesson, P.L. (2004) Pediatric Brain and Spine: An Atlas of MRI and Spectroscopy. Springer-Verlag, New York, p. 283

[20] Whitby, E.H., Griffiths, P.D., Rutter, S., Smith, M.F., Sprigg, A., Ohadike, P., Davies, N.P., Rigby, A.S. and Paley, M.N. (2004) Frequency and Natural History of Subdural Haemorrhages in Babies and Relation to Obstetric Factors. The Lancet, 363, 846-851.

[21] Rice, H.E., Frush, D.P., Farmer, D. and Waldhausen, J.H., APSA Education Committee (2007) Review of Radiation Risks from Computed Tomography: Essentials for the Pediatric Surgeon. Journal of Pediatric Surgery, 42, 603-607.

\section{Abbreviations}

CT scan-computed tomographic scanning

DAI-diffuse axonal injury

TBI-traumatic brain injury

MRI-magnetic resonance imaging

GCS_-glasgow coma scale

ICP_intracranial pressure 